\title{
Electronic Properties of Star-Shaped Oligofluorenes Containing an Isotruxene Core: Interplay of Para and Ortho Conjugation Effects in Phenylene-Based $\pi$ Systems
}

\author{
Jye-Shane Yang,* Hsin-Hau Huang, and Jinn-Hsuan Ho \\ Department of Chemistry, National Taiwan University, Taipei, Taiwan 10617
}

Received: January 16, 2008; Revised Manuscript Received: April 20, 2008

\begin{abstract}
The synthesis, photophysics, cyclic voltammetry, spectroelectrochemistry, and electrogenerated chemiluminescence (ECL) properties of a series of unsymmetrical star-shaped oligophenylenes IT1-IT4 are reported. The electronic couplings among the three oligofluorene arms in IT1-IT4 are strong due to the para-ortho branched isotruxene core. The ortho conjugation effect results in band splitting in the absorption spectra for both the neutral and the radical ionic form with a stronger effect for the latter. However, such an ortho conjugation effect becomes weaker as the oligofluorene arms are longer. The same fluorescence maxima displayed by IT2-IT4 suggest that the exciton coherence size (or the bound electron-hole pair) is no larger than 16 phenylene rings. The little chain-length dependence of the first reduction and oxidation potentials for IT1-IT4 suggests that the reversible electron-transfer processes of the neutral species are mainly associated with the isotruxene core. The ECL of IT1-IT4 is from the singlet excited state, but the spectra are red shifted with respect to the fluorescence spectra of dilute solutions due to the reabsorption effect. Our results also reveal that the meta conjugation interactions in the previously reported $C_{3}$-symmetrical truxene-oligofluorene analogs T1-T4 (Kanibolotsky, A. L.; Berridge, R.; Skabara, P. J.; Perepichka, I. F.; Bradley, D. D. C.; Koeberg, M. J. Am. Chem. Soc. 2004, 126, 13695-13702) are rather weak.
\end{abstract}

\section{Introduction}

The electronic properties of a variety of organic $\pi$-conjugated systems have been investigated in search of optimum materials for applications in optoelectronic devices. Of those, phenylenebased $\pi$-conjugated oligomers and polymers have emerged as the most promising candidates because of their efficient blue emission, high charge-carrier mobility, and great thermal and electrochemical stability. ${ }^{1-5}$ To achieve both features of high solubility and strong intramolecular conjugation interactions (electronic couplings), ring-bridged phenylene derivatives such as alkyl- or aryl-substituted fluorenes (1), ${ }^{3}$ indenofluorenes (2), ${ }^{4}$ and the elongated analogs 5 have become the most popular building blocks. In this context, polyfluorene (PF), poly-2,8indenofluorene (PIF), and ladder-type poly-p-phenylene (LPPP) constitute an important class of linear rod-shaped $\pi$-conjugated systems in contemporary electronic organic materials. ${ }^{2-5}$

Two-dimensional star-shaped $\pi$-conjugated systems have recently received more and more attention. ${ }^{6-10}$ For one reason, they generally possess superior solubility and film-forming properties as compared with the one-dimensional rod-shaped counterparts. ${ }^{78}$ For another reason, the increased dimensionality for the star- versus rod-shaped compounds can effectively reduce the anisotropy of the optical and charge-transport properties in thin solid films. ${ }^{9}$ Whereas these features are attractive in constructing organic light-emitting devices and solar cells, the reduced propensity of crystalline packing for them in thin films might hurt the charge mobility. ${ }^{7}$ To balance the reduction of intermolecular charge mobility, a possible strategy is to increase the intramolecular one. Indeed, recent studies have shown that star-shaped compounds containing a planarized rigid core such as truxene $\left(3, R_{1}=R_{2}=H\right)$ could maintain high charge

\footnotetext{
* Corresponding author. E-mail: jsyang@ntu.edu.tw.
}

mobilities, presumably due to increased intramolecular $\pi$-delocalization interactions. ${ }^{10}$

During the past decade, many truxene-derived star-shaped or dendritic $\pi$-conjugated systems were reported and investigated as blue light-emitting materials, ${ }^{11,12}$ light-harvesting chromophores,${ }^{13}$ fluorescent probes,${ }^{14}$ nonlinear optical materials, ${ }^{15}$ organic semiconductors, ${ }^{10}$ or hole-transport materials. ${ }^{16}$ An important structural feature of truxene is the $C_{3}$-symmetrical scaffold, where the three peripheral phenylene rings are all metasubstituted to the central ring. Recent studies have shown that the degree of conjugation interactions through a meta-phenylene strongly depends on the nature of $\pi$-conjugated backbones, ${ }^{17}$ the attached functional groups, ${ }^{18}$ and the electronic states (ground or excited) ${ }^{19}$ and it is generally weaker than that through a para or ortho one. ${ }^{17-20}$ Whereas this feature allows fine-tuning of the electronic properties of truxene-based materials, it might become a drawback when strong electronic couplings among the $\pi$ segments are desired. Indeed, it has recently been shown that para-ortho-branched phenylacetylene monodendrons display better light-harvesting properties than the meta-meta-branched counterparts. ${ }^{21}$

Isotruxene $\left(4, \mathrm{R}_{1}=\mathrm{R}_{2}=\mathrm{H}\right)$ is an isomer of truxene and simultaneously possesses the para-, meta-, and ortho-substituted patterns for the phenylene rings. Such a difference from the case of truxene has led to a significant difference in the absorption spectra (Figure 1). The broader and more red-shifted absorption bands for isotruxene versus truxene indicate the presence of much stronger electronic couplings among the phenylenes. However, it should be noted that there exists small but noticeable absorptions in the range of $300-350 \mathrm{~nm}$ for truxene (Figure 1, inset), indicating the presence of finite metaconjugation interactions. Although the electronic features of isotruxene versus truxene have been uncovered for more than 45 years $^{22}$ and the chemistry of the latter has been widely explored, ${ }^{11-16}$ the corresponding chemistry of the former is 


\section{CHART 1}

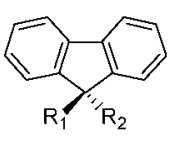

1

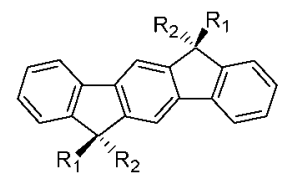

2

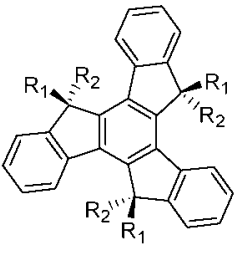

3

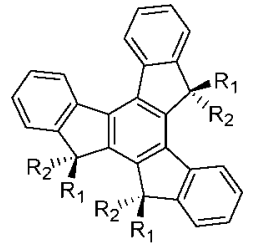

4

\section{CHART 2}

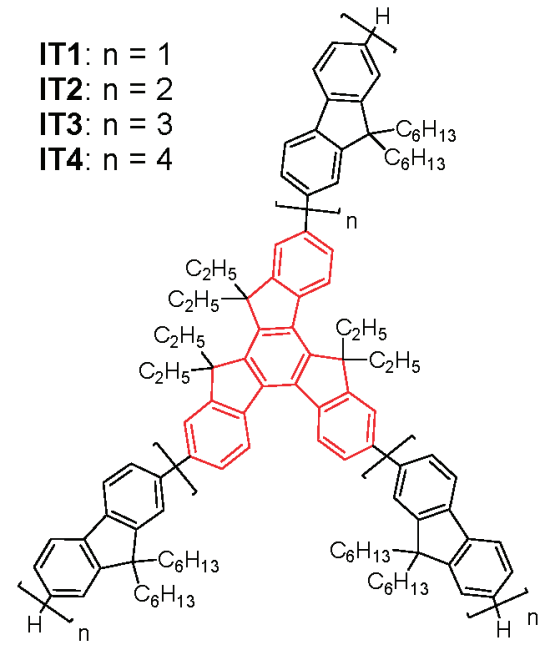

largely unknown. We recently reported the first star-shaped $\pi$-conjugated isotruxene derivative with a structure analogous to compound IT1 (i.e., the hexyl substituents on the fluorenes were replaced by ethyl groups) and showed that it displays promising physical properties. ${ }^{23}$ More specifically, compared with the truxene-oligofluorene analogs T1-T4, ${ }^{12}$ the isotruxene derivative displays much higher glass transition temperature $\left(T_{\mathrm{g}}\right)$ and requires shorter solubilizing alkyl chains for solubility, lower oxidation potential for generating the hole carrier, and shorter $\pi$-conjugated backbone for achieving blue light emission. ${ }^{23}$ To further understand the chain-length effect on the interplay of para-, meta-, and ortho-conjugation interactions in star-shaped oligophenylenes, we have prepared compounds IT1-IT4 and investigated their photophysical and electrochemical properties, including electronic spectra, fluorescence lifetimes, cyclic voltammetry, spectroelectrochemsitry, and electrogenerated chemiluminescence (ECL). In this paper, not only these results but also the comparisons among IT1-IT4, T1-T4, and rodshaped oligofluorenes are provided.

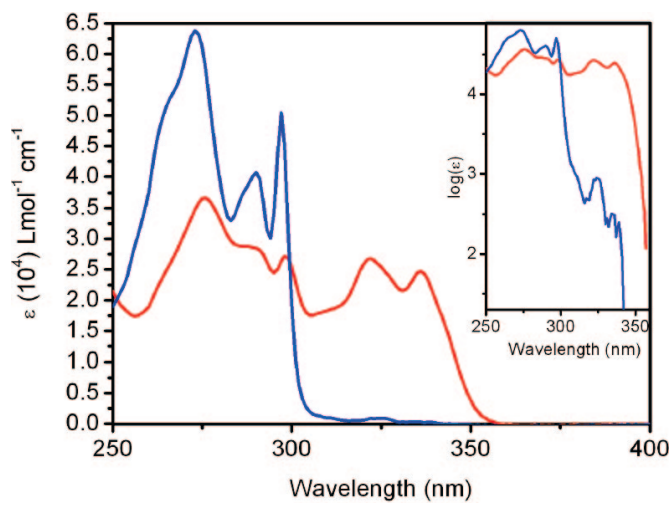

Figure 1. Absorption spectra of truxene (blue) and isotruxene (red) in THF with two different intensity scales, the molar absorptivity $(\epsilon)$, and $\log \epsilon$ (inset).

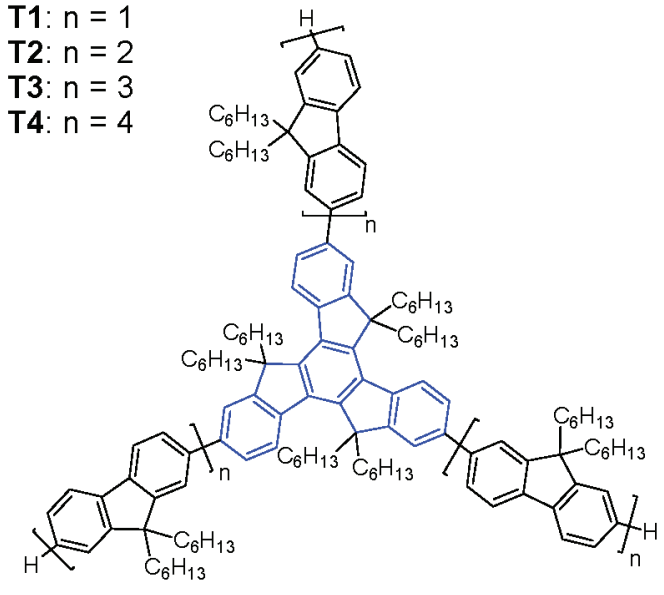

\section{Experimental Section}

General Methods. All of the spectral and electrochemical data were collected at room temperature $\left(23 \pm 1{ }^{\circ} \mathrm{C}\right)$. In addition, except for the working electrode, all electrochemical studies adopted a Pt wire as a counter electrode, a Ag wire as a reference electrode, and $0.1 \mathrm{M} \mathrm{Bu}_{4} \mathrm{NPF}_{6}$ as electrolyte. $\mathrm{UV}$-visible spectra of both the neutral and the oxidized forms of IT1-IT4 were measured on a Cary300 double beam spectrophotometer. The electrochemical oxidation experiments were carried out with $0.01 \mathrm{mM}$ substrates in $\mathrm{CH}_{2} \mathrm{Cl}_{2}$, a $1 \mathrm{~mm}$ quartz cell, and a Pt grid as a working electrode. Fluorescence spectra were recorded on a PTI QuantaMaster C-60 spectrometer and corrected for the response of the detector. The optical density of the toluene solution of IT1-IT4 was about 0.1 at the wavelength of excitation. A $\mathrm{N}_{2}$-bubbled solution of anthracence $\left(\Phi_{\mathrm{f}}=0.27 \text { in hexane }\right)^{24}$ was used as a standard for the fluorescence quantum yield measurement of IT1-IT4 under $\mathrm{N}_{2-}$ bubbled toluene solutions with solvent refractive index correction. An error of $\pm 10 \%$ was estimated for the fluorescence quantum yields. Fluorescence decays were determined by the Edinburgh FLS920 spectrometer with a gated hydrogen arc lamp using a scatter solution to profile the instrument response function. The goodness of the nonlinear least-squares fit was judged by the reduced $\chi^{2}$ value $(<1.2$ in all cases), the randomness of the residuals, and the autocorrelation function. The cyclic voltammetry (CV) and differential pulse voltammetry (DPV) were recorded on a CHI 612B electrochemical analyzer, and a glassy carbon served as the working electrode. The substrates are approximately $1 \mathrm{mM}$ in $\mathrm{CH}_{2} \mathrm{Cl}_{2}, \mathrm{THF}$, or benzene/ $\mathrm{MeCN}$ mixed solvents. The ECL experiments were conducted with a setup consisting of an F-3010 fluorescence spectrophotometer and a CV-27 potentiostat with a computer interface for the control of potential pulses (pulse width $=0.3 \mathrm{~s}$ ). The substrate concentration was $1 \mathrm{mg} / \mathrm{mL}$ in $1: 1$ or $2: 1$ benzene/ $\mathrm{MeCN}$ mixed solvents, and a $\mathrm{Pt}$ grid served as a working 


\section{SCHEME 1}

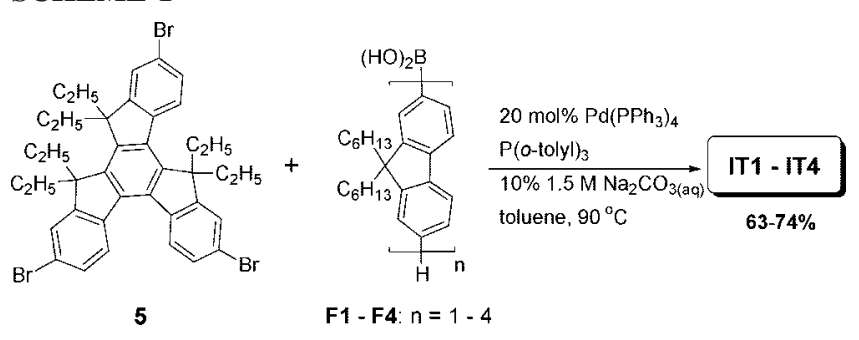

electrode. The electrode surfaces were prepared freshly before each electrochemical experiment. The glassy carbon electrode was rubbed against alumina paste followed by rinsing with deionized water and $\mathrm{CH}_{3} \mathrm{CN}$ and then wiping with high-quality lint-free tissue. The Pt and Ag wire electrodes were cleaned by rinsing with dilute nitric acid and then by deionized water, and they were finally fired with a naked flame to ensure maximum cleanliness of the electrode. All reported potentials were calibrated using ferrocene as an internal standard, taking $E^{o} \mathrm{Fc} /$ $\mathrm{Fc}+=0.424$ versus SCE. Thermogravimetric analysis (TGA) was performed with a TA 5100 thermal analysis system using dry nitrogen as a carrier gas at a flow rate of $60 \mathrm{~mL} \mathrm{~min} \mathrm{~m}^{-1}$. The TGA experiments were conducted from room temperature to $600{ }^{\circ} \mathrm{C}$ with a linear heating rate of $10^{\circ} \mathrm{C} \mathrm{min}^{-1}$.

Materials. All commercially available materials were used as received. Solvents for organic synthesis were reagent grade or HPLC grade but all were HPLC grade for spectral and electrochemical studies. THF was dried by sodium metal, and $\mathrm{CH}_{2} \mathrm{Cl}_{2}, \mathrm{CH}_{3} \mathrm{CN}$, and benzene were dried by calcium hydride and distilled before use. Detailed structural characterization data for new compounds (i.e., IT1-IT4) are provided as Supporting Information.

\section{Results and Discussion}

Synthesis. The synthetic strategy for IT1-IT4 resembles that for T1-T4 by attaching the oligofluorene arms of corresponding length $(\mathbf{F 1}-\mathbf{F 4})$ to the central isotruxene core (5) through the Suzuki coupling reaction (Scheme 1). The synthetic procedures for both the oligofluorene-2-boronic acids F1-F4 ${ }^{12}$ and the tribromoisotruxene $5^{23}$ have been previously reported. The yields and structural characterization data for IT1-IT4 are supplied in the Supporting Information. It should be noted that, unlike the hexyl groups in the truxene core of T1-T4, the isotruxene core in IT1-IT4 adopts the shorter ethyl chains as solubilizers in order to keep the hexaalkyl substituted isotruxene intermediate (4) in a solid form at room temperature for the purpose of facile purification. A lower melting point for isotruxene $\left(224{ }^{\circ} \mathrm{C}\right)$ versus truxene $\left(>300{ }^{\circ} \mathrm{C}\right)^{22}$ reflects its lower molecular symmetry. For the solubilizers in the fluorene arms, we maintain the use of hexyl groups in order to have the same oligofluorene arms as T1-T4 for better comparison of their electronic properties. The TGA 5\% decomposition temperatures for IT1IT4 are in the range $390-403{ }^{\circ} \mathrm{C}$ (see Supporting Information for details), comparable to those of T1-T4 $\left(401-415^{\circ} \mathrm{C}\right) .{ }^{12}$

Photophysics. The normalized absorption and fluorescence spectra for IT1-IT4 in toluene are shown in Figure 2, and the corresponding spectral data are summarized in Table 1. The absorption spectrum for IT1 displays two absorption bands at 349 and $380 \mathrm{~nm}$ as a result of ortho-conjugation-induced band splitting. It should be noted that both ortho- and meta- but not para-conjugation can lead to band splitting. ${ }^{25,26}$ In addition, the size of band splitting (i.e., the separation of peak maxima) and the intensity of the longer wavelength band are generally greater

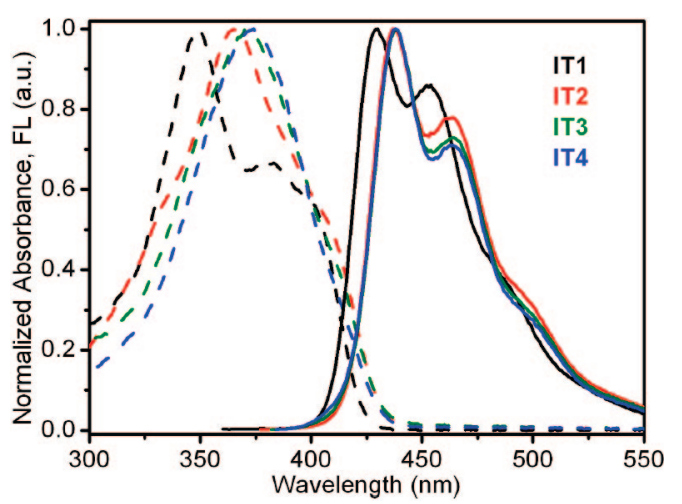

Figure 2. Normalized absorption (dash) and fluorescence (full) spectra of IT1-IT4 in toluene.

TABLE 1: Photophysical Data for IT1-IT4 and T1-T4 in Toluene $^{a}$

\begin{tabular}{lllcrrr}
\hline compd & \multicolumn{1}{c}{$\log \epsilon$} & $\lambda_{\mathrm{abs}}(\mathrm{nm})$ & \multicolumn{1}{c}{$\lambda_{\mathrm{fl}}(\mathrm{nm})$} & $\Phi_{\mathrm{fl}}$ & $\begin{array}{c}\tau_{\mathrm{fl}} \\
(\mathrm{ns})\end{array}$ & $\begin{array}{c}\mathrm{k}_{\mathrm{fl}} \\
\left(10^{8} \mathrm{~s}^{-1}\right)\end{array}$ \\
\hline IT1 & $5.02,4.85$ & 349,380 & 430,453 & 0.77 & 1.1 & 7.0 \\
IT2 & 5.27 & 367 & 438,464 & 0.79 & 0.9 & 8.8 \\
IT3 & 5.44 & 372 & 438,464 & 0.78 & 0.8 & 9.8 \\
IT4 & 5.58 & 374 & 438,464 & 0.78 & 0.7 & 11.4 \\
T1 & 4.97 & 343 & $375,396,416 \mathrm{sh}$ & 0.70 & & \\
T2 & 5.50 & 360 & $399,422,443 \mathrm{sh}$ & 0.83 & & \\
T3 & 5.61 & 370 & $408,431,460 \mathrm{sh}$ & 0.83 & & \\
T4 & 5.67 & 374 & $411,436,460 \mathrm{sh}$ & 0.86 & &
\end{tabular}

${ }^{a}$ Data for T1-T4 are from ref 12.

for ortho- than for meta-substitution. Figure 1 has provided one example for comparing the ortho- and meta-conjugation effect on band splitting: whereas both the meta- and the orthoconjugated pattern in isotruxene can contribute to the observation of two absorption bands of vibrational structures located at 260-305 and 305-355 nm, the much weaker intensity for the longer wavelength band $(305-345 \mathrm{~nm})$ of the meta-conjugated truxene system clearly suggests that the band splitting in isotruxene is mainly due to the ortho-conjugation interactions. The origin of band splitting has been ascribed to symmetryinduced configuration interactions. ${ }^{25,26}$ It is interesting to note that such a band splitting becomes weaker, and thus the bandwidth becomes narrower as the oligofluorene arms become longer. In the case of IT2, the spectrum displays a single maximum at $367 \mathrm{~nm}$ with shoulders at both sides, presumably due to two largely overlapped bands. For IT3 and IT4, the band splitting cannot be visually detected, because their spectra only show one single intense absorption band. Nonetheless, the band half-width $\left(4400-5500 \mathrm{~cm}^{-1}\right)$ is somewhat larger than that for rod-shaped oligofluorenes $\left(<4000 \mathrm{~cm}^{-1}\right) .{ }^{27}$ Regarding the fact that the para-conjugated oligophenylene chain in IT3 and IT4 contains as many as 15 and 19 phenylene rings, respectively, electronic excitation could be dominated by the para-conjugated configurations, and the meta- or ortho-conjugation effect is prominent only when the para-conjugated $\pi$-segments are short.

Regarding the fluorescence spectra, all four compounds of IT1-IT4 display the $0-0$ and $0-1$ vibrational bands. Unlike the absorption maxima that continue to move to the red, the fluorescence maxima of IT2-IT3 are essentially the same and red shifted by only $8 \mathrm{~nm}$ with respect to IT1. The absence of further spectral shift for IT3 and IT4 versus IT2 explicitly indicates that the exciton coherence size is no larger than 16 phenylene rings. A faster spectral saturation for fluorescence versus absorption with increasing the conjugation length is also known for the rod-shaped polyfluorenes, and the emitting unit 
is of approximately 6 fluorene units, corresponding to 12 phenylene rings. ${ }^{27}$ Recent single molecular spectroscopic studies on ladder-type oligophenylenes and polymers further revealed that the exciton coherence size is of 11-12 phenylene units (i.e., the emitting unit), but the exciton localization length (i.e., the absorbing unit) is at least twice this size. ${ }^{28}$ Since the paraconjugated chain in IT2-IT4 contains 11-19 phenylene rings, which is long enough to accommodate the exciton, the location of exciton might be mainly in the para-conjugated chain, although the possibility of it centering around the isotruxene core cannot be excluded.

The difference in the relative intensity of the $0-0$ and the $0-1$ bands of IT1-IT4 also deserves comments. The intensity ratio of the $0-1$ versus $0-0$ band $\left(I_{01} / I_{00}\right)$ is related to the Huang-Rhys factor $(S)$ via $I_{01} / I_{00}=S$ and in turn is related to the excited-state relaxation energy $\left(E_{\text {rel }}\right)$ via $E_{\text {rel }}=S v$, with $v$ being the energy of the associated vibrational mode..$^{29,30}$ Thus, the smaller the ratio of $I_{01} / I_{00}$, the weaker the vibronic coupling in the excited state, and the lower the relaxation energy. The size of $I_{01} / I_{00}$ decreases in the order IT1 $>$ IT2 $>$ IT3 $>$ IT4 (Figure 2), which suggests that structural relaxation between the ground $\left(\mathrm{S}_{0}\right)$ and the fluorescing state $\left(\mathrm{S}_{1}\right)$ becomes less as the size of the $\pi$ system becomes larger. Similar observations have also been found for the rod-shaped $\pi$-conjugated systems, including oligofluorenes. ${ }^{30}$ The decreased electronic coupling in larger $\pi$ systems is a consequence of the increased delocalization of the excited-state wave function.

Table 1 also shows the fluorescence quantum efficiencies $\left(\Phi_{\mathrm{ff}}\right)$ and fluorescence lifetimes $\left(\tau_{\mathrm{ff}}\right)$ for IT1-IT4 in toluene. Whereas the values of $\Phi_{\mathrm{fl}}$ are near 0.8 for all cases and independent of the conjugation length, the value of $\tau_{\mathrm{fl}}$ progressively decreases as the oligofluorene arms become longer. As a result, the fluorescence rate constant $\left(k_{\mathrm{fl}}=\Phi_{\mathrm{f}} / \tau_{\mathrm{ff}}\right)$ decreases in the order IT4 $>$ IT3 $>$ IT2 $>$ IT1. Such a trend is consistent with the larger optical transition probability between the $S_{0}$ and $S_{1}$ states, as reflected by the larger $\log \varepsilon$ values, and with the lesser extent of excited-state structural relaxation, as reflected by the smaller ratio of $I_{01} / I_{00}$, for larger oligomers. A decrease of fluorescence lifetime with an increase of chain length has also been observed for rod-shaped oligofluorenes. ${ }^{30,31}$ However, the fluorescence lifetimes of IT1-IT4 are slightly larger than those of rod-shaped oligofluorenes of the same number of phenylene rings. This again reflects the difference of ortho- versus para-conjugation on optical transition probability.

There are several intriguing differences in the electronic spectra between IT1-IT4 and T1-T4 (Table 1). ${ }^{12}$ First, no explicit band splitting in the absorption spectra could be observed for the truxene systems T1-T4. Second, the fluorescence spectra are more structured for T1-T4 versus IT1-IT4. Third, the maxima of the $0-0$ fluorescence band $(375-411 \mathrm{~nm})$ for T1-T4 are all blue-shifted relative to IT1 $(430 \mathrm{~nm})$. Finally, the fluorescence as well as the absorption spectra of T1-T4 shows continued red shift with the increase of the oligofluorene chain length. All of these spectral differences indicate that the excited-state wave function is much less delocalized in T1-T4 versus IT1-IT4. In other words, para-conjugation interactions prevail and meta-conjugation interactions are negligible in T1T4 so that their electronic properties are more like those of a single oligofluorene arm. ${ }^{32}$ In this context, it is particularly interesting to compare the spectra of IT1 and T4. The whole $\pi$ system of IT1 contains only 10 phenylene rings, but T4 possesses 10 rings in each arm, and there are 28 rings in the whole molecule. However, the fluorescence $0-0$ band is at longer wavelength for IT1 $(430 \mathrm{~nm})$ versus T4 $(411 \mathrm{~nm})$.

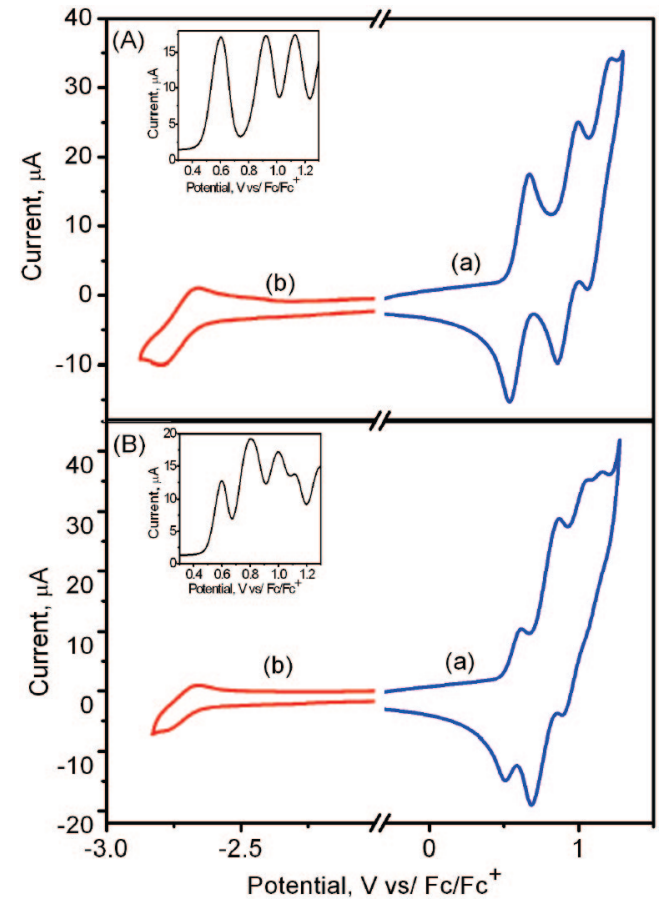

Figure 3. Cyclic voltammogram of (A) IT1 and (B) IT3 in (a) dichloromethane (for oxidation) and (b) THF (for reduction) and the differential pulse voltammogram for oxidation (inset); electrolyte 0.1 $\mathrm{M} \mathrm{Bu}_{4} \mathrm{NPF}_{6}$; scan rate $100 \mathrm{mV} \mathrm{s}^{-1}$.

Assuming that the larger band gap for T4 versus IT1 is due to localized (i.e., in one oligofluorene arm) versus fully delocalized exciton, corresponding to a length of 10 phenylene rings for both cases, the deviations in peak maxima between IT1 and T4 again reflect the difference of the phenylene connection patterns (i.e., para-othro vs para only). Since ortho-conjugationinduced band splitting often reduces the oscillator strength for the $S_{0} \rightarrow S_{1}$ transition as compared with the para-conjugated isomers, ${ }^{25,26}$ this might account for the somewhat lower $\log \varepsilon$ values for IT1-IT4 versus T1-T4 (Table 1). Nonetheless, their fluorescence quantum yields are comparable.

Electrochemistry. The electrochemical behavior of IT1-IT4 has been investigated by cyclic voltammetry (CV) and differential pulse voltammetry (DPV). Figure 3 shows two typical cyclic voltammograms and differential pulse voltammograms (inset) represented by IT1 and IT3. CVs of IT1 and IT3 show a single quasi-reversible cathodic wave of similar peak potentials before background reduction of the solvent/supporting electrolyte (in THF). However, their anodic behavior (in dichloromethane) is quite different. Whereas IT1 displays three sequential one-electron processes, the anodic CV of IT3 shows three reversible and one quasi-reversible waves in the same window. Except for the second peak being a two-electron transfer, the others are more likely one-electron transfer processes. The two-electron transfer assignment for the second anodic wave of IT3 was based on the size of peak current and $\Delta E_{\mathrm{pa}-\mathrm{pc}}$, which are approximately twice those of the first one. The CV and DPV spectra of IT2 and IT4 are provided in Supporting Information (Figure S1), and the detailed CV and DPV data for IT1-IT4 are summarized in Table 2. These results (i.e., $\mathbf{I T 4}^{+6}$ vs $\mathbf{I T 3}^{+5}$ vs $\mathbf{I T 2}^{+4}$ vs $\mathbf{I T 1}^{+3}$ ) appear to show that the larger is the $\pi$ system, the more of charges can be generated. Recent studies on Na reduction of rod-shaped polyfluorenes in THF have suggested that every $\sim 2$ repeating unit (i.e., 4 rings) can accommodate one anion (negative polaron). ${ }^{33}$ Our results 
TABLE 2: Electrochemical Data for IT1-IT4 and T1-T4 ${ }^{a}$

\begin{tabular}{lclc}
\hline compd & \multicolumn{1}{c}{$E_{o x}{ }^{1 / 2},{ }^{b, c} \mathrm{~V}$} & $E_{\text {red }}{ }^{1 / 2}, c, d \mathrm{~V}$ & $\Delta E_{o x}{ }^{e}$ \\
\hline IT1 & $0.61\left(1 \mathrm{e}^{-}\right), 0.93\left(1 \mathrm{e}^{-}\right), 1.15\left(1 \mathrm{e}^{-}\right)$ & -2.74 & 0.32 \\
IT2 & $0.60\left(1 \mathrm{e}^{-}\right), 0.81\left(1 \mathrm{e}^{-}\right), 0.97\left(1 \mathrm{e}^{-}\right)$, & -2.72 & 0.22 \\
& $1.20\left(1 \mathrm{e}^{-}\right)$ & \\
IT3 & $0.60\left(1 \mathrm{e}^{-}\right), 0.82\left(2 \mathrm{e}^{-}\right), 1.00\left(1 \mathrm{e}^{-}\right)$, & -2.71 & 0.2 \\
& $1.12\left(1 \mathrm{e}^{-}\right)$ & & \\
IT4 & $0.60\left(1 \mathrm{e}^{-}\right), 0.77\left(2 \mathrm{e}^{-}\right), 0.92\left(2 \mathrm{e}^{-}\right)$, & -2.73 & 0.16 \\
& $1.11\left(1 \mathrm{e}^{-}\right)$ & & \\
T1 & $0.80\left(1 \mathrm{e}^{-}\right), 1.05\left(2 \mathrm{e}^{-}\right)$, & -2.8 & 0.25 \\
T2 & $0.76\left(1 \mathrm{e}^{-}\right), 0.84\left(1 \mathrm{e}^{-}\right), 1.03\left(1 \mathrm{e}^{-}\right)$ & -2.74 & 0.08 \\
T3 & $0.76\left(1 \mathrm{e}^{-}\right), 0.94\left(1 \mathrm{e}^{-}\right)$ & $-2.70,-2.83$ & 0.18 \\
T4 & $0.74\left(1 \mathrm{e}^{-}\right), 0.87\left(1 \mathrm{e}^{-}\right)$ & $-2.66,-2.74$ & 0.13
\end{tabular}

${ }^{a}$ Data for T1-T4 are from ref $12 .{ }^{b}$ In dichloromethane solution. ${ }^{c}$ Potentials are reported $\mathrm{vs} \mathrm{Fc} / \mathrm{Fc}^{+} .{ }^{d}$ In THF solution. ${ }^{e} \Delta E_{o x}=E_{o x 2}$ $-E_{o x l}$.

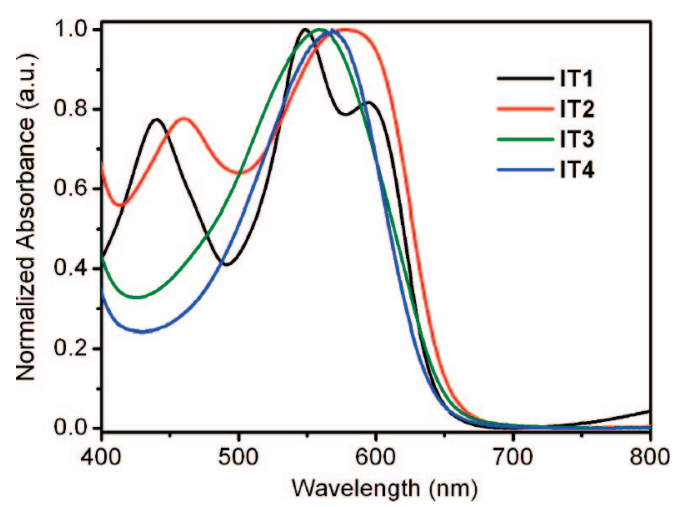

Figure 4. Absorption spectra of DDQ-oxidized IT1-IT4 in $\mathrm{CF}_{3} \mathrm{CO}_{2} \mathrm{H} /$ $\mathrm{CH}_{2} \mathrm{Cl}_{2}$ (1:9).

TABLE 3: UV-vis Absorption Maxima for DDQ and Electrochemically Oxidized IT1-IT4 in Solutions

\begin{tabular}{lllc}
\hline compd & \multicolumn{1}{c}{$\begin{array}{c}\lambda_{\text {abs }}{ }^{a}, \mathrm{~nm} \\
(\text { DDQ-oxidized) }\end{array}$} & \multicolumn{1}{c}{$\begin{array}{c}\lambda_{\text {abs }}{ }^{b}, \mathrm{~nm} \\
\text { (radical cation) }\end{array}$} & $\begin{array}{c}\lambda_{\text {abs }}{ }^{b}, \mathrm{~nm} \\
\text { (dication) }\end{array}$ \\
\hline IT1 & $439,549,594$ & $348,439,549,594$ & \\
IT2 & 460,579 & $340,454,590$ & \\
IT3 & 559 & 458,595 & 537 \\
IT4 & 568 & 461,602 & 560
\end{tabular}

${ }^{a}$ In $\mathrm{CF}_{3} \mathrm{CO}_{2} \mathrm{H} / \mathrm{CH}_{2} \mathrm{Cl}_{2}(1: 9 \mathrm{v} / \mathrm{v})$ solution. ${ }^{b}$ In dichloromethane.

indicate that the cation (positive polaron) in IT1-IT4 can also be accommodated within 4 phenyl rings.

According to the data in Table 2, the reduction potentials $\left(-2.71 \sim-2.74 \mathrm{~V}\right.$ vs $\left.\mathrm{Fc} / \mathrm{Fc}^{+}\right)$and the first oxidation potentials $\left(0.60 \sim 0.61 \mathrm{~V}\right.$ vs $\left.\mathrm{Fc} / \mathrm{Fc}^{+}\right)$of IT1-IT4 are approximately the same, indicating of negligible chain-length effect on the oxidation and reduction of the neutral form. However, the potentials for the second anodic wave are chain-length dependent, and it is negatively shifted with elongating the oligofluorene arms. This in turn leads to a decrease of the peak splitting $\left(\Delta E_{o x}\right)$ between the first $\left(E_{o x l}\right)$ and the second $\left(E_{o x 2}\right)$ anodic waves with increasing the size of the oligomers (i.e., IT1 > IT2 > IT3 > IT4). These observations appear to suggest that the isotruxene core dominates the initial oneelectron oxidation and reduction processes. However, once the radical cations are formed during the oxidation process, the charge is delocalized and thus affects the next anodic electron transfer. The decreased value of $\Delta E_{o x}$ for the larger oligomers can be attributed to a decreasing Coulombic repulsion between the two charges.

The chain-length effect on CV observed for IT1-IT4 is somewhat different from that for T1-T4 under the same

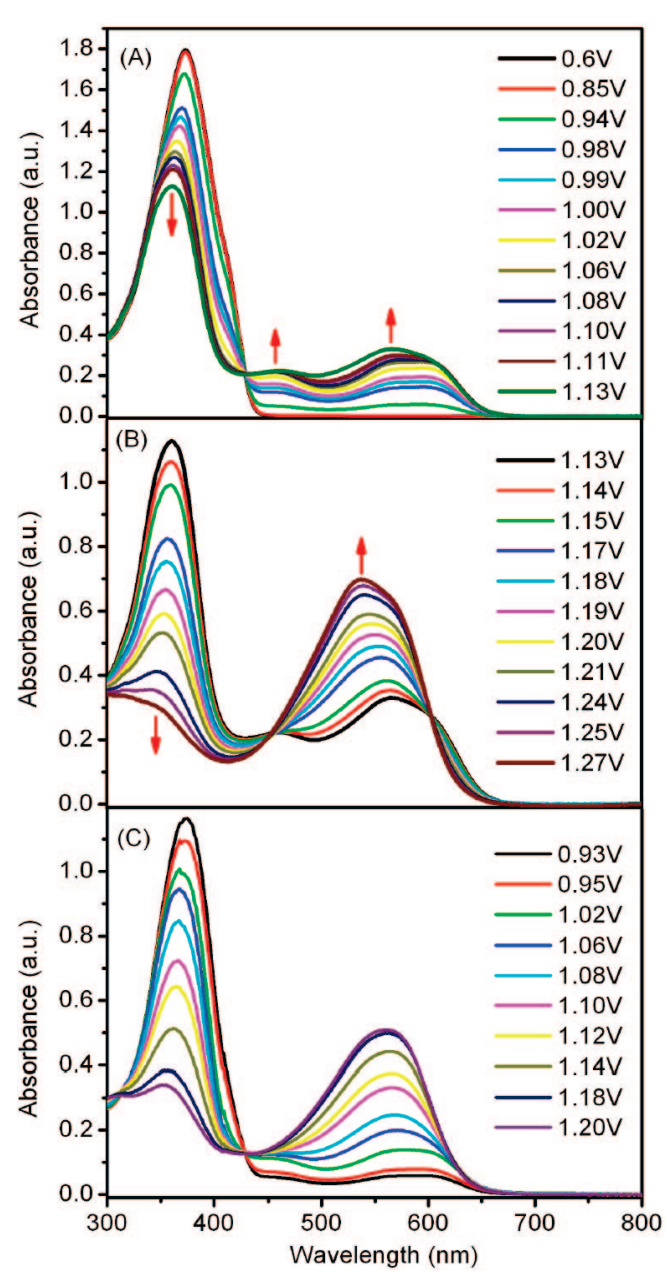

Figure 5. Spectroelectrochemistry of (A) IT3 at the first stage $(0.6 \sim 1.13 \mathrm{~V}$ vs $\mathrm{Ag}$ wire) showing an isosbestic point at $428 \mathrm{~nm}$, (B) IT3 at the second stage (1.13 1.27 V vs Ag wire) showing isosbestic points at 457 and $603 \mathrm{~nm}$, and (C) IT4 (0.6 1.20 V vs Ag wire) showing an isosbetic point at $430 \mathrm{~nm}$.

TABLE 4: Fluorescence and ECL Peaks and Redox Potentials for IT1-IT4 in Benzene/MeCN Mixed Solvents (1.0 $\mathrm{mg} / \mathrm{mL}$ ) and Energetics of the Ion Annihilation Reaction for $\mathbf{E C L} \mathbf{L}^{a}$

\begin{tabular}{lccccccc}
\hline & $\begin{array}{c}\lambda_{\mathrm{FL}}, \\
\mathrm{nm}\end{array}$ & $\begin{array}{c}\lambda_{\mathrm{ECL}}, \\
\mathrm{nm}\end{array}$ & $\begin{array}{c}E_{00} \\
(\mathrm{eV})\end{array}$ & $\begin{array}{c}E_{\text {red }}{ }^{1 / 2} \\
(\mathrm{vs} \mathrm{SCE})\end{array}$ & $\begin{array}{c}E_{o x}{ }^{1 / 2} \\
(\mathrm{vs} \mathrm{SCE})\end{array}$ & $\begin{array}{c}-\Delta G^{\mathrm{o}^{c}} \\
(\mathrm{eV})\end{array}$ & $\begin{array}{c}-\Delta H^{\mathrm{o}^{d}} \\
(\mathrm{eV})\end{array}$ \\
\hline IT1 & 455 & 453 & 3.00 & -2.15 & $1.12,1.18$ & 3.27 & 3.17 \\
IT2 & 465 & 460 & 2.95 & -2.10 & $1.12,1.36$ & 3.22 & 3.12 \\
IT3 & 468 & 463 & 2.95 & -2.12 & $1.12,1.29$ & 3.24 & 3.14 \\
IT4 & 469 & 465 & 2.95 & -2.12 & $1.12,1.27$ & 3.24 & 3.14
\end{tabular}

${ }^{a}$ In benzene/MeCN solution (1:1 for IT1 and IT2 and 2:1 for IT3 and IT4). ${ }^{b}$ The value of $E_{00}$ was obtained from the intersection of normalized absorption and fluorescence spectra of dilute solutions. ${ }^{c}-\Delta G^{\mathrm{o}}=E_{\text {oxI }}{ }^{1 / 2}-E_{\text {red }}{ }^{1 / 2}{ }^{d}-\Delta H^{0}=-\Delta G 0.1$.

experimental conditions. For facile comparison, the $\mathrm{CV}$ data of T1-T4 from ref 12 are also shown in Table 2. First, unlike the insensitive dependence of the first redox potentials on the size of the isotruxene systems, the redox potentials for both oxidation and reduction of the neutral T1-T4 become lower as the oligomers are larger. Second, unlike the monotonous decrease in $E_{o x 2}$ and $\Delta E_{o x}$ as elongating the oligofluorene chains for the isotruxene systems, the corresponding values of T1-T4 show no regular trends. However, in later CV studies in benzene/ acetonitrile mixed solvents, ${ }^{34}$ a trend on $\Delta E_{o x}$ is present: namely, T1 $(0.23 \mathrm{~V}) \sim \mathrm{T} 2(0.24 \mathrm{~V})>\mathbf{T} 3(0.16 \mathrm{~V})>\mathbf{T} 4(0.12 \mathrm{~V})$. 

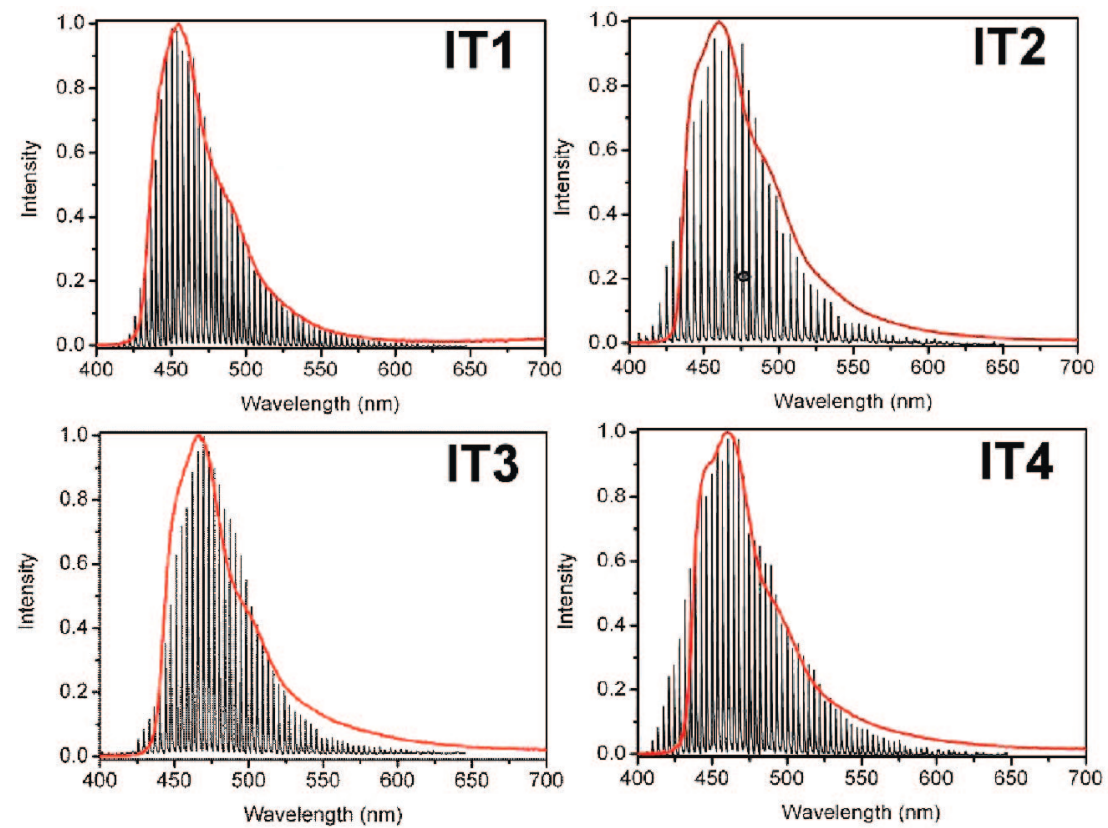

Figure 6. ECL (black) and fluorescence (red) spectra of IT1-IT4 in benzene/MeCN (1:1 for IT1 and IT2 and 2:1 for IT3 and IT4) with $0.3 \mathrm{~s}$ pulses by alternating the potential between +1.15 and $-2.20 \mathrm{~V}$ vs $\mathrm{Ag}$ wire.

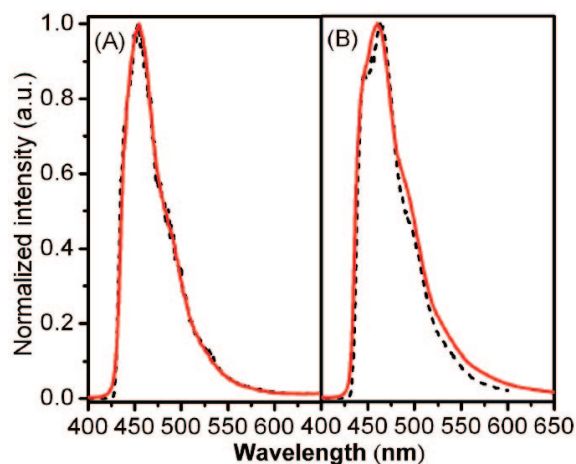

Figure 7. Comparison of the simulated fluorescence spectra using eq 1 (red) and the observed fluorescence spectra (black) recorded under the ECL conditions for (A) IT1 and (B) IT2.

Third, the second anodic wave for T1 was reported to be a twoelectron transfer step, but it is a one-electron step for T2-T4. Furthermore, a third one-electron anodic wave was recorded for T2 but not for T3 and T4. All of the above features suggest that the overall chain-length effect on the electrochemical properties is more complicated for T1-T4 versus IT1-IT4. Nonetheless, on the basis of the lower values of $E_{o x l}$ and larger $\Delta E_{\text {ox }}$ for IT1-IT4 versus T1-T4, we can conclude that electronic couplings among the arms are larger for the former species, which is consistent with the conclusions based on electronic spectra.

Absorption Spectra of Oxidized IT1-IT4. Regarding the more prominent chain-length effect on the redox potentials for the radical cation versus neutral form of IT1-IT4, the UV-vis absorption spectra of their radical cations have been investigated in order to examine the interplay of para- and ortho-conjugation effects in the charged species. For comparison, the spectra were recorded with two different methods of oxidation: namely, chemical oxidation with excess ( $\sim 100$ equivalents) 2,3 -dichloro5,6-dicyano-1,4- benzoquinone (DDQ) in $\mathrm{CF}_{3} \mathrm{CO}_{2} \mathrm{H} / \mathrm{CH}_{2} \mathrm{Cl}_{2}$ (1:9 $\mathrm{v} / \mathrm{v})^{35}$ and electrochemical oxidation with varying the potential from +0.6 (the first oxidation potential) to around $+1.2 \mathrm{~V}$ (the last electron-transfer process before background oxidation) in $\mathrm{CH}_{2} \mathrm{Cl}_{2}$.
In a one-electron description, radical cations (polarons) are expected to have two absorption bands with one in the visible and the other in the near IR regions, resulting from the transitions of SOMO $\rightarrow$ LUMO and HOMO $\rightarrow$ SOMO, respectively. ${ }^{36}$ Indeed, two strong absorption bands located at 580 and $2480 \mathrm{~nm}$ have been reported for the radical cations of rod-shaped polyfluorenes. ${ }^{33}$ As shown in Figure 4, the DDQoxidized IT1-IT4 also display intense absorption bands in the visible-light region. Whereas IT3 and IT4 display only a single band, there are two distinct absorption bands for IT1 and IT2. It should be noted that the longer wavelength band for IT1 shows clear $0-0$ and $0-1$ vibrational structures. These absorption maxima are reported in Table 3 . In the case of spectroelectrochemistry, the absorption bands in the visible region for IT1 (Figure S3) are exactly the same as those generated by DDQ oxidation (Figure 4). An increase of the applied potential simply leads to an increase of the peak intensities without changing the absorption profile. This suggests that the first generated radical cation of IT1 is rather stable and escapes away from the electrode so that further oxidation of them at higher potentials is minimal. This is also consistent with the presence of an isosbestic point at $418 \mathrm{~nm}$ for the $\mathbf{I T 1} \rightarrow$ IT1 $^{+}{ }^{+}$conversion. The absorption spectra for the IT $2 \rightarrow$ IT $2{ }^{+}$conversion (Figure S3) also display an isosbestic point $(427 \mathrm{~nm})$, and the absorption bands in the visible region are essentially located at the same positions as those upon DDQ oxidation (Table 3). In contrast, IT3 and IT4 display a two-stage spectral change (Figure 5). At lower potentials (the first stage), two absorption bands located in the visible region are present, but at higher potentials (the second stage), they emerge into one band located between the two original bands. Since the CV experiments suggest a twoelectron transfer process for the first-step oxidation of neutral IT3 and IT4 (Table 2), the first and second stages might correspond to the neutral $\rightarrow$ radical cation and the radical cation $\rightarrow$ dication conversion, respectively. By comparing with the absorption spectra of the neutral form (Figure 1), the phenomenon of ortho-conjugation-induced band splitting appears to be more significant in the radical cations, which accounts for the observation of two absorption bands in the visible region for 
IT3 $^{+}$and IT4 $^{+}$as well as IT1 ${ }^{+}$and IT2 ${ }^{+}$(Figure S4). The absence of band splitting in the absorption spectra of the radical cations of T1-T4 ${ }^{12}$ again suggests a weak meta-conjugation effect even in the oxidized form. It should also be noted that dications of $\pi$-conjugated polymers could be characterized as either bipolarons or two polarons on the basis of their absorption spectra, where a single absorption band lying between the two bands of polarons is expected for the formation of bipolarons. ${ }^{36}$ Recent studies on polythiophene and polyfluorene have suggested that the dication character depends on the chain length and the two-polaron character is more important in longer polymers. ${ }^{33,36}$ Regarding the similar location of absorption bands for the radical cations and dications of IT3 and IT4, the latter species might also be of two polarons rather than bipolarons. Accordingly, the absence of band splitting for the dications of IT3 and IT4 might indicate that the two polarons are more localized as a consequence of Coulombic repulsion.

Electrogenerated Chemiluminescence. Light emission resulting from the combination of two charged radical ions (ion annihilation rections) generated by electrolysis of substrates in solutions is called electrogenerated chemiluminescence (ECL). ${ }^{37}$ The ECL properties of many organic conjugated systems, ${ }^{38}$ including the oligofluorenes T1-T4, ${ }^{34}$ have been investigated. This is in part due to the fact that the light-emitting mechanism for ECL is similar to that in OLED devices, and thus studies on the former could provide insights into the latter systems. In this context, the ECL behavior of IT1-IT4 have been investigated and compared to that of T1-T4.

The ECL experiments were carried out with a sample concentration of $1.0 \mathrm{mg} / \mathrm{mL}$ in benzene/MeCN (1:1 or $2: 1)$ mixed solvents. The use of benzene solvent is for the purpose of solubility, and a higher fraction of benzene in the mixed solvents is required for the larger oligomers IT3 and IT4. In addition, the use of equal mass instead of equal moles per volume for IT1-IT4 is to reduce the formation of micorcrystals of the larger oligomers under such high concentrated solutions. The CV behavior of IT1-IT4 in the mixed solvents (Figure S2) resembles that in pure dichloromethane or THF (vide supra), and the first reduction $(-2.10 \sim-2.15 \mathrm{~V}$ vs SCE) and oxidation $(1.12 \mathrm{~V}$ vs SCE) potentials are reported in Table 4. Voltage was pulsed between the first oxidation $(1.15 \mathrm{~V})$ and reduction peak $(-2.20 \mathrm{~V})$ for all four cases. The results are shown in Figure 6 and Table 4. For comparison, the fluorescence spectra determined under the same concentration of substrates are also shown in Figure 6.

As shown in Figure 6, the fluorescence spectra match excellently with the ECL spectra for all four cases of IT1-IT4. Evidently, the observed ECL results from the singlet excited state, the so-called S-route mechanism. ${ }^{35}$ Indeed, the enthalpies of ion annihilation ( $\Delta H$ in Table 4), as calculated from the redox potentials $\left(E^{o}{ }_{\text {red }}\right.$ and $\left.E^{o}{ }_{\text {ox }}\right)$ are much greater than the singlet state 0-0 transition energy $\left(E_{00}\right)$. In other words, the energy from the annihilation reactions of the radical cations and radical anions is sufficient for the generation of a singlet excited state. It should be noted that the fluorescence peak maxima are red shifted by approximately $25 \mathrm{~nm}$ with respect to their dilute solutions. To demonstrate that such a spectral shift is simply due to light reabsorption under the optically dense solutions rather than to intermolecular interactions, the reabsorption effect on fluorescence has been simulated, to a first approximation, using eq $1:{ }^{39}$

$$
\mathrm{F}^{\prime}(v)=\mathrm{F}(v)\left[10^{-\varepsilon(v) c l}\right]
$$

where $\mathrm{F}(v)$ is the fluorescence spectrum of highly dilute solution, $\mathrm{F}^{\prime}(v)$ is the distorted fluorescence spectrum after reabsorption, $\varepsilon(v)$ is the molar absorptivity of absorption spectrum, $c$ is the concentration of IT1-IT4, and $l$ is the thickness through which the fluorescence photons have to escape. As represented by IT1 and IT2 (Figure 7), the simulated fluorescence spectra after reabsorption agree well with the fluorescence spectra recorded under the ECL conditions. In other words, the fluorescence around the $0-0$ vibrational peaks (Figure 2 ) has been largely reabsorbed by the optically dense solutions and thus the fluorescence maxima shift to the red, leading to fluorescence maxima very close to the $0-1$ peaks in Table 1 . The reabsorption phenomenon is also present in the fluorescence spectra of conjugated oligomers and polymers in thin solid films. ${ }^{40}$

Like the cases of IT1-IT4, the symmetrical systems T1-T4 were also shown to display ECL via the S-route mechanism. ${ }^{33}$ In addition, the ECL maxima for T2-T4 are all similar to those of their fluorescence $0-1$ band of dilute solutions. However, interpretation of the ECL spectrum of T1 is much less straightforward, because it shows two peaks with one at 377 $\mathrm{nm}$, the same as the fluorescence $0-0$ band of dilute solutions, and the other at $470 \mathrm{~nm}$, much longer wavelength than the fluorescence $0-1$ band $(398 \mathrm{~nm})$. Disregarding the origins of these observations, the difference in the ECL behavior between T1 and IT1 reveals that the difference in the shape and/or the inherent electronic properties of $\pi$ systems can significantly affect the intermolecular ion annihilation reactions.

\section{Conclusions}

We have carried out the first systematic studies on the chainlength effect on electronic properties of unsymmetrical starshaped oligophenylenes based on the isotruxene derivatives IT1IT4. The planar para-ortho-branched iostruxene core in IT1IT4 allows strong conjugation interactions among the oligofluorene arms in the ground and the excited states and the oxidized form. As a result, the photophysical and electrochemical properties such as the spectral maxima, the exciton coherence size, the fluorescence lifetime, the polaron deformation length, and the dication character observed for these two-dimensional $\pi$ systems are comparable to those for one-dimensional para-conjugated oligofluorenes of the same number of phenylene rings. Compounds IT1-IT4 also display promising electrochemical stability and electrogenerated chemiluminescent properties. The distinct electronic properties between the IT1-IT4 and the corresponding truxene derivatives T1-T4 reflect that the conjugation pattern of the core plays a crucial role in determining the electronic properties of star-shaped $\pi$ systems. The para-ortho-branched isotruxene scaffold should be a useful building block for constructing multidimensional $\pi$ systems, particularly aromatic hydrocarbons, of strong electronic couplings among the $\pi$ segments.

Acknowledgment. Financial support for this research was provided by the National Science Council of Taiwan, ROC, and National Taiwan University.

Supporting Information Available: Structural characterization data, ${ }^{1} \mathrm{H}$ and ${ }^{13} \mathrm{C}$ NMR spectra, MALDI-TOF mass spectra, additional CV and spectroelectrochemical spectra, and TGA scans for IT1-IT4. This material is available free of charge via the Internet at http://pubs.acs.org.

\section{References and Notes}

(1) Conjugated Polymers: Theory, Synthesis, Properties, and Characterization: Skotheim, T. A., Reynolds, J. R., Eds.; CRC Press: Boca Raton, FL, 2007. 
(2) (a) Setayesh, S.; Grimsdale, A. C.; Weil, T.; Enkelmann, V.; Müllen, K.; Meghdadi, F.; List, E. J. W.; Leising, G. J. Am. Chem. Soc. 2001, 123 , 946-953. (b) Grimsdale, A. C.; Müllen, K. Macromol. Rapid Commun. 2007, 28, 1676-1702.

(3) (a) Geng, Y.; Trajkovska, A.; Katsis, D.; Ou, J. J.; Culligan, S. W.; Chen, S. H. J. Am. Chem. Soc. 2002, 124, 8337-8347. (b) Wong, K.-T.; Chien, Y.-Y.; Chen, R.-T.; Wang, C.-F.; Lin, Y.-T.; Chiang, H.-H.; Hsieh, P.-Y.; Wu, C.-C.; Chou, C.-H.; Su, Y. O.; Lee, G.-H.; Peng, S.-M. J. Am Chem. Soc. 2002, 124, 11576-11577. (c) Wu, C.-c.; Liu, T.-L.; Hung, W.Y.; Lin, Y.-T.; Wong, K.-T.; Chen, R.-T.; Chen, Y.-M.; Chien, Y.-Y.J. Am. Chem. Soc. 2003, 125, 3710-3711.

(4) (a) Merlet, S.; Birau, M.; Wang, Z. Y. Org. Lett. 2002, 4, $2157-$ 2159. (b) Vak, D.; Lim, B.; Lee, S.-H.; Kim, D.-Y. Org. Lett. 2005, 7 4229-4232.

(5) (a) Jacob, J.; Sax, S.; Piok, T.; List, E. J. W.; Grimsdale, A. C.; Müllen, K. J. Am. Chem. Soc. 2004, 126, 6987-6995. (b) Jacob, J.; Sax, S.; Gaal, M.; List, E. J. W.; Grimsdale, A. C.; Müllen, K. Macromolecules 2005, 38, 9933-9938. (c) Wu, Y.; Zhang, J.; Bo, Z. Org. Lett. 2007, 9 4435-4438. (d) Zhou, G.; Baumgarten, M.; Müllen, K. J. Am. Chem. Soc. 2007, 129, 12211-12221.

(6) (a) Cho, B. R.; Chajara, K.; Oh, H. J.; Son, K. H.; Jeon, S.-J. Org Lett. 2002, 4, 1703-1706. (b) Zhou, X.-H.; Yan, J.-C.; Pei, J. Org. Lett. 2003, 5, 3543-3546. (c) Li, B.; Li, J.; Fu, Y.; Bo, Z. J. Am. Chem. Soc. 2004, 126, 3430-3431. (d) Sun, M.; Fu, Y.; Li, J.; Bo, Z. Macromol. Rapid Commun. 2005, 26, 1064-1069. (e) Yamaguchi, Y.; Ochi, T.; Miyamura, S.; Tanaka, T.; Kobayashi, S.; Wakamiya, T.; Matsubara, Y.; Yoshida, Z. J. Am. Chem. Soc. 2006, 128, 4504-4505. (f) Zhao, Z.; Xu, X.; Xu, L.; Yu, G.; Lu, P.; Liu, Y. Synth. Met. 2007, 157, 414-420. (g) Cremer, J.; Briehn, C. A. Chem. Mater. 2007, 19, 4155-4165.

(7) (a) Han, Y.; Fei, Z.; Sun, M.; Bo, Z.; Liang, W.-Z. Macromol. Rapid Commun. 2007, 28, 1017-1023. (b) Kim, K. H.; Chi, Z.; Cho, M. J. Jin, J.-I.; Cho, M. Y.; Kim, S. J.; Joo, J.-s. Choi, D. H. Chem. Mater. 2007 $19,4925-4932$.

(8) Ponomarenko, S. A.; Kirchmeyer, S.; Elschner, A.; Huisman, B.H.; Karbach, A.; Drechsler, D. Adv. Funct. Mater. 2003, 13, 591-596.

(9) (a) Roquet, S.; Cravino, A.; Leriche, P.; Alévêque, O.; Frère, P.; Roncali, J. J. Am. Chem. Soc. 2006, 128, 3459-3466. (b) Roncali, J.; Leriche, P.; Cravino, A. Adv. Mater. 2007, 19, 2045-2060.

(10) Sun, Y. M.; Xiao, K.; Liu, Y.; Wang, J. L.; Pei, J.; Yu, G.; Zhu, D. Adv. Funct. Mater. 2005, 15, 818-822.

(11) (a) Pei, J.; Wang, J.-L.; Cao, X.-Y.; Zhou, X.-H.; Zhang, W.-B. J. Am. Chem. Soc. 2003, 125, 9944-9945. (b) Cao, X.-Y.; Liu, X.-H.; Zhou, X.-H.; Zhang, Y.; Jiang, Y.; Cao, Y.; Cui, Y.-X.; Pei, J. J. Org. Chem. 2004, 69, 6050-6058. (c) Cao, X.-Y.; Zhou, X.-H.; Zi, H.; Pei, J Macromolecules 2004, 37, 8874-8882. (d) Cao, X.-Y.; Zhang, W.; Zi, H.; Pei, J. Org. Lett. 2004, 6, 4845-4848. (e) Zhang, W.; Cao, X.-Y.; Zi, H.; Pei, J. Org. Lett. 2005, 7, 959-962. (f) Jiang, Y.; Wang, J.-Y.; Ma, Y. Cui, Y.-X.; Zhou, Q.-F.; Pei, J. Org. Lett. 2006, 8, 4287-4290. (g) Zhang, W.-B.; Jin, W.-H.; Zhou, X.-H.; Pei, J. Tetrahedron 2007, 63, 2907-2914.

(12) Kanibolotsky, A. L.; Berridge, R.; Skabara, P. J.; Perepichka, I. F.; Bradley, D. D. C.; Koeberg, M. J. Am. Chem. Soc. 2004, 126, 1369513702.

(13) (a) Duan, X.-F.; Wang, J.-L.; Pei, J. Org. Lett. 2005, 7, 40714074. (b) Wang, J.-L.; Luo, J.; Liu, L.-H.; Zhou, Q.-F.; Ma, Y.; Pei, J Org. Lett. 2006, 8, 2281-2284. (c) Sánchez, L.; Martin, N.; GonzalezCantalapiedra, E.; Echavarren, A. M.; Aminur-Rahman, G. M.; Guldi, D. M. Org. Lett. 2006, 8, 2451-2454.

(14) Yuan, M.-S.; Liu, Z.-Q.; Fang, Q. J. Org. Chem. 2007, 72, 79157922

(15) Sanguinet, L.; Williams, J. C.; Yang, Z.; Twieg, R. J.; Mao, G.; Singer, K. D.; Wiggers, G.; Petschek, R. G. Chem. Mater. 2006, 18, 42594269.

(16) Kimura, M.; Kuwano, S.; Sawaki, Y.; Fujikawa, H.; Noda, K.; Taga, Y.; Takagi, K. J. Mater. Chem. 2005, 15, 2393-2398.

(17) (a) Yamaguchi, Y.; Kobayashi, S.; Wakamiya, T.; Matsubara, Y.; Yoshida, Z. Angew. Chem., Int. Ed. 2005, 44, 7040-7044. (b) Song, C.; Swager, T. M. Macromolecules 2005, 38, 4569-4576. (c) Priego, E. M. Sánchez, L.; Herranz, M. A.; Martín, N.; Viruela, R.; Ortí, E. Org. Biomol. Chem. 2007, 5, 1201-1209.

(18) (a) Bangal, P. R.; Lam, D. M. K.; Peteanu, L. A.; Van der Auweraer, M. J. Phys. Chem. B 2004, 108, 16834-16840. (b) Yamaguchi, Y.; Ochi, T.; Miyamura, S.; Tanaka, T.; Kobayashi, S.; Wakamiya, T.; Matsubara, Y.; Yoshida, Z. J. Am. Chem. Soc. 2006, 128, 4504-4505.
(19) (a) Díez-Barra, E.; García-Martínez, J. C.; Merino, S.; del Rey, R.; Rodríguez-López, J.; Sánchez-Verdú, P.; Tejeda, J. J. Org. Chem. 2001, 66, 5664-5670. (b) Gaab, K. M.; Thompson, A. L.; Xu, J.; Martinez, T. J.; Bardeen, C. J. J. Am. Chem. Soc. 2003, 125, 9288-9289. (c) Thompson, A. L.; Gaab, K. M.; Xu, J.; Bardeen, C. J.; Martinez, T. J. J. Phys. Chem. A 2004, 108, 671-682. (d) Ranasinghe, M. I.; hager, M. W.; Gorman, C. B.; Goodson, T., III. J. Phys. Chem. B 2004, 108, 8543-8549. (e) Thompson, A. L.; Ahn, T.-S.; Thomas, K. R. J.; Thayumanavan, S.; Martinez, T. J.; Bardeen, C. J. J. Am. Chem. Soc. 2005, 127, 16348-16349.

(20) (a) Karabunarliev, S.; Baumgarten, M.; Tyutyulkov, N.; Müllen, K. J. Phys. Chem. 1994, 98, 11892-11901. (b) Hong, S. Y.; Kim, D. Y.; Kim, C. Y.; Hoffmann, R. Macromolecules 2001, 34, 6474-6481. (c) Tammer, M.; Horsburgh, L.; Monkman, A. P.; Brown, W.; Burrows, H. D. Adv. Funct. Mater. 2002, 12, 447-454. (d) Chu, Q.; Pang, Y.; Ding, L.; Karasz, F. E. Macromolecules 2002, 35, 7569-7574. (e) Pogantsch, A.; Mahler, A. K.; Hayn, G.; Saf, R.; Stelzer, F.; List, E. J. W.; Brédas, J.-L.; Zojer, E. Chem. Phys. 2004, 297, 143-151. (f) Cao, X.-Y.; Zi, H.; Zhang, W.; Lu, H.; Pei, J. J. Org. Chem. 2005, 70, 3645-3653. (g) Oliva, M. M.; Casado, J.; Hennrich, G.; Navarrete, J. T. L. J. Phys. Chem. B 2006, 110, 19198-19206.

(21) (a) Peng, Z.; Pan, Y.; Xu, B.; Zhang, J. J. Am. Chem. Soc. 2000, 122, 6619-6623. (b) Melinger, J. S.; Pan, Y.; Kleiman, V. D.; Peng, Z.; Davis, B. L.; McMorrow, D.; Lu, M. J. Am. Chem. Soc. 2002, 124, 1200212012. (c) Pan, Y.; Lu, M.; Peng, Z.; Melinger, J. S. J. Org. Chem. 2003, 68, 6952-6958.

(22) Lang, K. F.; Zander, M.; Theiling, E. A. Chem. Ber. 1960, 93, $321-325$.

(23) Yang, J.-S.; Lee, Y.-R.; Yan, J.-L.; Lu, M.-C. Org. Lett. 2006, 8, 5813-5816.

(24) Dawson, W. R.; Windsor, M. W. J. Phys. Chem. 1968, 72, 32513260 .

(25) (a) Lewis, F. D.; Kalgutkar, R. S.; Yang, J.-S. J. Am. Chem. Soc. 1999, 121, 12045-12053. (b) Yang, J.-S.; Liau, K.-L.; Tu, C.-W.; Hwang, C.-Y. J. Phys. Chem. A 2005, 109, 6450-6456.

(26) Murrell, J. N. The Theory of the Electronic Spectra of Organic Molecules; John Wiley and Sons: New York, 1963.

(27) (a) Klaerner, G.; Miller, R. D. Macromolecules 1998, 31, 20072009. (b) Jo, J.; Chi, C.; Höger, S.; Wegner, G.; Yoon, D. Y. Chem. Eur. J. 2004, 10, 2681-2688.

(28) Schindler, F.; Jacob, J.; Grimsdale, A. C.; Scherf, U.; Müllen, K.; Lupton, J. M.; Feldmann, J. Angew. Chem., Int. Ed. 2005, 44, 1520-1525.

(29) Bässler, H.; Schweitzer, B. Acc. Chem. Res. 1999, 32, 173-182.

(30) Wasserberg, D.; Dudek, S. P.; Meskers, S. C. J.; Janssen, R. A. J. Chem. Phys. Lett. 2005, 411, 273-277.

(31) Chi, C.; Im, C.; Wegner, G. J. Chem. Phys. 2006, 124, 024907.

(32) Oliva, M. M.; Casado, J.; Navarrete, J. T. L.; Berridge, R.; Skabara, P. J.; Kanibolotsky, A. L.; Perepichka, I. F. J. Phys. Chem. B 2007, 111, 4026-4035

(33) Takeda, N.; Asaoka, S.; Miller, J. R. J. Am. Chem. Soc. 2006, 128, $16073-16082$.

(34) Omer, K. M.; Kanibolotsky, A. L.; Skabara, P. J.; Perepichka, I. F.; Bard, A. J. J. Phys. Chem. B 2007, 111, 6612-6619.

(35) Sep, W. J.; Verhoeven, J. W.; de Boer, T. J. Tetrahedron 1979, $35,2161-2168$.

(36) van Haare, J. A. E. H.; Havinga, E. E.; van Dongen, J. L. J.; Janssen, R. A. J.; Cornil, J.; Brédas, J.-L. Chem. Eur. J. 1998, 4, 1509-1522.

(37) (a) Electrogenerated Chemiluminescence, Bard, A. J., Ed.; Marcel Dekker: New York, 2004. (b) Richter, M. M. Chem. Rev. 2004, 104, 30033036.

(38) (a) Choi, J.-P.; Wong, K.-T.; Chen, Y.-M.; Yu, J.-K.; Chou, P.-T.; Bard, A. J. J. Phys. Chem. B 2003, 107, 14407-14413. (b) Elangovan, A.; Chen, T.-Y.; Chen, C.-Y.; Ho, T.-I. Chem. Commun. 2003, 2146-2147. (c) Lin, J.-H.; Elangovan, A.; Ho, T.-I. J. Org. Chem. 2005, 70, 7397-7407. (d) Ho, T.-I.; Elangovan, A.; Hsu, H.-Y.; Yang, S.-W. J. Phys. Chem. B 2005, 109, 8626-8633. (e) Rashidnadimi, S.; Hung, T. H.; Wong, K. T.; Bard, A. J. J. Am. Chem. Soc. 2008, 130, 634-639.

(39) Dhami, S.; De Mello, A. J.; Rumbles, G.; Bishop, S. M.; Phillips, D.; Beeby, A. Photochem. Photobiol. 1995, 61, 341-346.

(40) Yang, J.-S.; Yan, J.-L.; Hwang, C.-Y.; Chiou, S.-Y.; Liau, K.-L.; Tsai, H.-S. G.; Lee, G.-H.; Peng, S.-M. J. Am. Chem. Soc. 2006, 128, 14109-14119.

JP800448P 